\title{
Excellence in Strategic Planning
}

\author{
Georg Winckler
}

\section{Introduction}

Strategic planning is a means for a university to tackle the big issues with which it is confronted and to improve its competitive position. In order to gain the status of excellence, it is worthwhile that the university studies past models of success. Interesting examples are the so-called research-intensive university, the entrepreneurial university, or the university as knowledge enterprise. Ultimately, excellence depends on transforming the existing profile to one that successfully copes with future challenges.

\section{Designing the Planning Process}

\subsection{General Remarks}

In business administration studies, there is a common understanding that a strategy has to deal with the central issues of an establishment. It should focus on factors that determine the company's success. As a consequence, a strategic plan needs to answer the "big" questions a company is confronted with. In game theory, however, the term "strategy" is more generally defined. There, a strategy is any of the options a player can choose within more or less well-defined rules, where the outcome of choosing an option depends not only on a player's actions, but also on the actions of others. Strategic planning then looks for those strategies that are best, depending on other players' actions.

When designing a strategic plan for a university one should be aware of both definitions: (1) focusing on the "big" decisions an institution has to make and (2) taking into account the strategic interdependence with the outside world.

\footnotetext{
G. Winckler $(\bowtie)$

University of Vienna, Vienna, Austria

e-mail: georg.winckler@univie.ac.at
} 
Finding a strategy for a university raises other issues too. A strategic plan should shape its identity and its profile. To do so, the plan needs to be consistent and longterm oriented. Since any identity is also defined by the values and standards an institution or an individual stands for, a strategic plan should explicitly indicate the value orientation on which it is based. In addition, the planning and the implementation of a strategy have to motivate the individuals who work for an institution. These individuals must readily recognize the chosen strategy as useful in tackling the "big" issues and as being potentially feasible. The pursuit of a strategy, however ambitiously its goals are set, should not be perceived as beyond reach.

Of course, a strategic plan should not only specify the long-term options, nor should it only articulate the values and standards within the framework of which these choices are made. It should also include the concrete actions, which are required or recommended when implementing a given strategy. This action plan has to indicate when and by which means intermediate steps will be taken. Finally, strategic controlling should provide feedback for correcting the course of action during the implementation phase.

\subsection{Pitfalls in the Process of Strategic Planning}

The process of strategic planning is fraught with many problems and pitfalls.

How to avoid them?

The first pitfall consists of excessive egocentric thinking. Any institution has to be aware of the outside world, which does not only react, but also acts. There are fierce competitors on all sides. Opportunities for cooperation abound. In order to assess how the outside world perceives an institution and what potential for joint actions with cooperators exists, an institution should start the process of strategic planning with an analysis of the added value it yields to its relevant stakeholders.

To conduct this analysis of added value, it is helpful to examine the overall value which is created and then to remove the institution which wants to start the planning process from the picture. The analysis has to determine exactly which stakeholders will suffer which losses when the planning institution is out of the picture. In that way, the extra value an institution creates can be ascertained. Game theory now teaches us how to structure interactions with stakeholders so that the value added can be maintained or even increased. This approach to strategic planning helps to focus on others and avoids inward looking thinking and planning.

A second pitfall lies in accepting too many existing rules of the game. Excellence in performance, in contrast, is often achieved by complying with most of the rules, but in also inventing some new rules. Often, inventing these new rules seems to be difficult at the beginning, but after they have been decided upon and adapted, the result seems simple and clear. The critical question for finding such new rules is how to effectively organize collective intelligence within an institution. Outside advisors may also be helpful. 
A third pitfall might be mentioned too: the lack of backward reasoning. Many planners desire to reach the future by updating the present. Yet, a strategic approach requires that an aspiring vision is developed, that the values of the institution are stated, and that a point of time in the future is specified when the aspiring vision is supposed to be realized, while the stated values are maintained and in place. Then, given the endpoint of planning, backward reasoning should be used in order to derive what actions are necessary and when. Forward reasoning used exclusively might lead the planning institution to a state of uncontrolled dynamics. Note that backward deduction is the tool used in the theory of dynamic optimization.

\subsection{How to Begin a Strategic Planning Process Within a University?}

Let us illustrate how to begin a strategic planning process in the context of an excellent university. As an example, reference is made to Princeton University, a rather small Ivy League research university in the US, with only about 8000 students, but which is consistently ranked among the top ten universities in the world.

In a university such as Princeton University, the question of what its future should look like is regarded as very legitimate. However, when trying to answer this question within the framework of strategic planning, allergic reactions on campus emerge. Committees that collect data, lead assessments, and work out reports are quickly denounced as part of a bureaucratic, cumbersome effort that only leads to a nebulous "wish list". Many on campus think that the best way is to just let the future happen, through decentralized actions of departments only.

Yet, to overcome this fragmented approach, the newly appointed university president suggested another framework. To better shape Princeton's thinking about its future and about how the "big" issues with which Princeton University is confronted can be tackled, the president proposed to engage in strategic planning, so that Princeton's thinking is structured along prescribed lines. In addition, since the allocation of resources needs to be optimized, strategic planning has to set spending priorities for Princeton's budget.

As a consequence, the president started the process of strategic planning by raising four key questions (quotes from [1]).

- "How best can Princeton sustain teaching and research excellence that makes a difference in the world?" To offer the highest quality in research and scholarship is taken for granted at Princeton. The open issue, however, is what the university can actually do to make a difference in the world.

- "What new academic initiatives should Princeton pursue to address long-term issues of fundamental importance?" Addressing that question means moving into new fields of research such as neuroscience, but it also entails embracing old knowledge in a new way, e.g., to discuss ethical issues in the context of a globalized, digitalized world. 
- "What must we do to make service central to the mission of the University?" Princeton wants to better prepare its students for careers and lives "in the service of humanity". To serve humanity will become increasingly important, so Princeton wishes to be prominently engaged in this task.

- "How can Princeton enable more undergraduate students to contribute to the world"? Princeton aims at creating additional places for undergraduates. It will increase its socioeconomic diversity and the number of international exchange students. Undergraduate education has always been a cornerstone at Princeton and that obviously should remain so.

Princeton University will work through fall 2015 to develop a new strategic plan within which it will prioritize new initiatives over the next five to ten years. During that process, values and standards will be articulated against which Princeton will judge proposals that come forward later.

\subsection{Design of the Planning Process}

To summarize: any planning process should start with the assessment of challenges and evolving needs so that the planning institution focuses on its "big" issues. So as not to indulge in an egocentric planning process, the university should also learn how it is perceived from the outside. A first step in doing so is to develop a SWOT analysis (strengths, weaknesses, opportunities, threats). Then it should assess the added value it yields to its stakeholders.

A vision and a mission have to be determined which motivate staff and generate a specific profile. They should incorporate ambitious and coherent goals that are regarded as worth aspiring to and which are deemed to be potentially feasible. Values and quality standards such as academic freedom, diversity of students and staff, or community engagement have to be articulated and any strategic proposals will have to be evaluated against them. Finally, specific goals for a future date have to be set and then, with backward reasoning and by inventing some new rules in the game, an action plan should be decided upon. Instruments of strategic controlling have to be set up to guarantee that these goals are actually reached and to enable corrective measures when necessary.

\section{Examples of Strategy Models for Universities}

\subsection{Historic Perspective}

Nowadays it seems evident that leading universities place themselves somewhere in the triangle of higher education, research and innovation and, as a third mission, community service. This placement corresponds to the nature of a university 
as perceived today and all three items regularly appear in any university strategic plan. Yet, it is worth remembering that universities started their history differently and it may be that the future will again bring changes, with new challenges for universities' strategic planning.

For many centuries, the main task of universities consisted of teaching and learning only. The university was a community of masters and students ("universitas magistrorum et scholarium"), living together in colleges so that the transfer of knowledge, skills, and values from one generation to the next could easily take place on campus. The programs of these communities and their missions were ambitious and based on humanistic principles. In the charter of the University of Vienna, written in 1365, for example, the university was summoned to understand faith and thereby further it (in the faculty of theology), to enhance judicial equity (in the faculty of law), to serve the public good (in the faculty of medicine), and to foster human reasoning (in the faculty of philosophy).

There was no research. To listen to good teachers, students moved around Europe.

University rankings did not exist. However, it was well known around the year 1500 for example, that law was best taught at the University of Bologna, medicine at the University of Padova, and philosophy (the seven "artes liberales") at the Sorbonne in Paris [2]. The strategy of excellence for a university consisted in hiring the best teachers. Consequently, students would be attracted and thereby the university would be funded. At that time, the majority of university funding came from students.

As the advancement of the sciences gained momentum in the 18th century, and with the increased interest of the then emerging nation states in applying scientific knowledge to solve societal, economic, and military problems, European universities gradually evolved into research institutions dependent on state funding. Finally, innovation became a buzzword of the 21 st century. It originated in an economic debate, stressing the importance of science-based innovations for upgrading jobs and triggering growth in a globalized world.

\subsection{The Research-Intensive University and Its Strategies (Humboldt Model)}

The idea of a university as a "true" research university, which concentrates mainly on scientific discoveries and new scholarly insights, was developed in Germany approximately two hundred years ago. Then Wilhelm von Humboldt convinced the king and the state of Prussia to establish the Berlin University [3]. Prior to Humboldt, scholars such as Baruch Spinoza in the Netherlands had already stressed the role of scientific reasoning in explaining empirical observations and how reason may help to improve the conditions of life. These insights had already paved the way for the secularization of universities. 
This new type of university was designed according to philosophical ideas concerning the nature and the relevance of research. From there, a strategic plan of excellence was derived for the universities. Humboldt's proposal to establish the Berlin University was also a reaction to French state utilitarianism which, at that time, led to the closure of universities in France and in neighboring countries, and to the foundation of "écoles spéciales" (now "grandes écoles"), such as the École Polytechnique in 1794. With these drastic measures, France wanted to rapidly educate a technocratic, science trained, meritocratic elite who could make the new bourgeois state more powerful and more effective. In contrast to these state efforts in France, the Berlin University was freed from any necessity of purpose to be useful. The university was supposed to search for the scientific truth only and that was its goal per se. The strategy of engaging staff and students in pure research was the key for the idea of a university as advocated by Humboldt.

As a consequence, emphasis was laid on the basic sciences, the humanities, and research-oriented doctoral studies. Research and teaching should form a unity, not only in theory, but also in practice. Of course, Humboldt hoped that by only allowing pure and open research, not serving practical needs, the university would ultimately, via the publication of results and via the doctoral formation of students as young researchers ("Bildung durch Forschung"), generate wellbeing for the state, the society, and the economy.

In fact, the huge success of German research efforts in the 19th century, especially in the sciences such as physics or chemistry, in medicine, and in electrical engineering, led to the foundation of the industrial powerhouse of Germany which continues to flourish today. To emulate this success, Humboldt's idea of a research university was replicated in many European countries and even attained by, for example, the United States and Japan. There, new research universities with Ph.D programs started first in Baltimore in 1876 (Johns Hopkins University), then in Chicago in 1890 (University of Chicago), and in other places, and led to the foundation of universities in Tokyo and Kyoto. Ivy League universities in the US and the universities of Cambridge and Oxford in England followed with Ph.D programs in the 20th century.

The strategy and structure of the Humboldtian research university were designed in a simple way. Research and teaching strategies were fixed by a faculty, assuming that the professors of a faculty knew best what to do. Professorial freedom of research and teaching were even constitutionally guaranteed. All professors and students were obliged to strive after scientific truth only, and everyone was expected and encouraged to come up with new scientific insights. The academic freedom was complemented by a light collegial governance structure in the faculties, which were ruled by professorial collegial bodies. Adequate funding of the university came from the state in order to make sure that the university was not forced to pursue practical needs and was free to conduct basic research. Governmental supervision concentrated on preserving this true nature of research universities. University presidency was reduced to a representative function. Strategic planning for the future was carried out by the faculties where the existence of scientific wisdom in abundance was automatically assumed. 
Today, this elitist concept of a "true" Humboldtian research university is no longer possible. The massification of higher education within many universities, the specialization of knowledge within faculties, the quest for quickly applying new knowledge to industry, and the increased amounts of investments needed to bring the infrastructure of a university up to date, all necessitate institutional, not faculty strategies. In addition, governments were not able or not willing to increase the funding of research universities relative to the massification of higher education. As a consequence, universities were forced to specialize in some fields, to better allocate their resources internally, and to search for new ways of financing their activities besides state funding. What then remains from the elitist Humboldtian model of a research university in the 21 st century?

To answer that question it may be worthwhile to look at the recent strategy plan of the legal successor of the Berlin University, namely the Humboldt University of Berlin. Its plan was developed when this university participated in the German Excellence Initiative of 2012. Now Humboldt University can claim to have presented a strategic plan, which was honored by the federal government of Germany within its initiative to establish universities of excellence in the country.

The new Strategic Plan of the Humboldt University [4] named "Educating Enquiring Minds. Individuality-Openness-Guidance" accepts that some, not all, research areas will be strengthened. This extra funding of some excellent research clusters and newly established integrative research institutes implies that the university faculties no longer receive their traditional share of the budget. Consequently, the power of decision-making shifts increasingly to the university leadership.

Areas of excellence at Humboldt University refer to the life sciences, the research for global sustainability, the field of hybrid materials and functional systems and to the humanities. Although a disproportionate funding of faculties is now practiced, the targeted areas still constitute, all in all, a broad range of subjects of a traditional research university.

Besides these targeted research efforts in which $60 \%$ of the additional money of the excellence initiative of the government flows, young researchers get promoted. About $30 \%$ of the additional money is spent in recognizing personal strengths, allowing individuals to develop their research potential, and promoting the young research generation in their careers. The initiatives under this second heading contain programs such as "Humboldt Goes to School", quality programs for the bachelor studies (more research-based learning), the expansion of the "Humboldt Graduate School", research tracks for graduate students, the promotion of postdocs via fellowships and, finally, the setting up of a strategic innovation fund.

The third area of the new strategy plan addresses governance issues. About $10 \%$ of the extra money of the excellence initiative will be spent in this third area of administrative reform, which endeavors to establish a culture of enablement among administrative staff. It also involves a reform of existing faculties and aims at regrouping faculties and departments. Another program strengthens the deans in their decision-making powers and reinforces them as strategic links between 
the faculties and the university management. It is not yet clear what the outcome of the excellence strategy of Humboldt University will be and to what extent it will revive Humboldt's original ideas. At the end of 2017, the funding decision of the German government has to be renewed. Therefore, the result of implementing the new strategy is due for evaluation at that time by external peers. Yet the main aims of the strategy, to reinvigorate the Humboldtian ideas of strengthening pure research and of providing formation through research, all by extra state funding, and the aim to modernize the governance structure, will be implemented in a university with high student-staff ratios in many study programs. Mass university-wide education remains the norm. Potential conflicts among faculties and fields in which many students study may therefore arise. One of Humboldt's ideas, namely to create a uniformity of excellence within the whole university, will be at stake. Hence the sustainability of the new strategic plan of Humboldt University of Berlin hinges decisively on the adequacy of future funds, and on the strength of the new institutional leadership to overcome fragmented faculty interests.

\subsection{The Strategic Concept of an Entrepreneurial University}

The Humboldt model of a pure research university is based on a philosophical idea about the nature and relevance of research. This idea was put into practice about two hundred years ago. In contrast, the strategic concept of an entrepreneurial university is a construct suggested by Burton R. Clark who derived this construct from empirically observed cases of pro-active universities in the 1980s and 1990s. Prototypes of such pro-active universities, termed as entrepreneurial universities, are the University of Warwick in England, the University of Michigan in the US, and Monash University in Australia [5, 6].

The strategic plan of an entrepreneurial university typically focuses on reinforcing activities which transform the university from a state-led to an own-led institution. As a result, the university should be able to move fast, with high ambitions of its own, in the globalized environment of the 21st century. Of course, universities differ and, as a consequence, strategies need to also address the specialties of the institution. In addition, universities used the emerging entrepreneurialism to create spin-offs and start-ups, thereby bringing entrepreneurship into society.

In order to transform an originally state-led university into an entrepreneurial one, the strategic plan should concentrate on strengthening factors which act as catalysts for change. According to Clark there are five key factors to consider:

- Diversify the funding base: besides the general state funding, a university should try to secure means from other government sources and from private organized sources, especially from business firms and foundations. In addition, the university should generate some of its own income by fund-raising from alumni, from garnering research contracts, or from the transfer of knowledge. 
- Improve the steering capacity of the university. A university should display administrative strength at all levels. Change-oriented administrations are needed in all parts of a university. New administrators should increase income and control cost.

- Create units besides the traditional, discipline-centered departments. These units are best in pursuing problem-oriented research, be it interdisciplinary, trans-disciplinary, or at the margin of a traditional research field. All new units should have a high potential to gain scientific reputation and third party funding. New areas for teaching, such as lifelong learning, distance education, or the development of massively open online courses, could also be tackled by newly established units. As a consequence, the traditional departmental or faculty structure of a university is supplemented by a strong periphery, representing new research and teaching interests, challenging traditional departments and making them increasingly open to change.

- Support those departments which go for entrepreneurial actions. In doing so, teams within the traditional units become involved in the process of change. The university should ensure that these entrepreneurial actions are well managed by change-oriented administrators.

- Intensify the competition for outside reputation. Hire high-reputation academics from outside who in turn will attract excellent new faculty members and bright students. This will speed up the pace of change toward entrepreneurialism within the university.

The concept of an entrepreneurial university contains a strategic plan for change, from a state-led, bureaucratic, and slow-moving institution to a university being able to steer itself and to move fast. Clark's advice concerning the key factors of change was heeded by many world universities in their strategic plans, which aim to strengthen their autonomy and their world standings.

Note that entrepreneurialism does not necessarily imply a commercialization of the university. Rather the contrary: the more a university is successful in steering the above-mentioned activities, the more it is able to and capable of attaining increased reputation. By increasing and enhancing its reputation, a university will attract more long run, general research grants, thus reinforcing the freedom of research. The less a university is successful, the more it will become dependent on money only given for short-term purposes and for specific applications.

\subsection{The University as a Knowledge Enterprise in an Innovation-Driven Society}

An interesting further move toward knowledge entrepreneurialism of universities is offered by the "New American University" model, introduced by Arizona State University (ASU). Approximately ten years ago, this university reformulated its 
mission and strategic plan, endeavoring to inspire more creativity and innovation within the institution [7].

The main ideas of the new strategic concept have been derived in the context of new policies in the U.S. state of Arizona. This state, unlike the area of nearby Los Angeles, is characterized by an underbuilt and undifferentiated university infrastructure. Yet, this backward position allowed new pathways for development, which were laid down in an unconventional strategic plan for 2002-2012. The plan opted for a reconceptualization of a university.

There are four basic strategic goals.

- "Access and quality for all": This goal seems to be a contradiction in terms. This is especially so when an institution is confronted with limited financial means. Yet, ASU would appear to be on a growth trajectory where both strategic goals, access and quality, seem to be attainable. In 2013, for example, the number of enrollments had already approached 77,000 undergraduate, graduate, and professional students. Freshman numbers have increased in size by about $50 \%$ since 2002. Access for students from poor families (with annual income below 60.000 USD) has risen by $500 \%$. These students are able to graduate debt free from the university. By hiring new faculty, quality could also be improved.

- "National standings for colleges and schools in every field": ASU is constantly ranked among the top hundred universities in the world. Its research strength lies especially in engineering and computer sciences. Standings seem to improve according to various benchmarks.

- "Becoming a national comprehensive university": This goal is meant to build national and global distinction on the basis of comprehensiveness of the university.

- "Enhancing our local impact and social embeddedness": Although the university wants to be a top-notch research institution, it is strongly committed not to advance abstract knowledge per se. Instead, the university looks at the social, economic, cultural, and environmental impact of its knowledge advancement. In light of this perspective, the university has founded a school of sustainability, introduced a study of religion and conflict, and established a biodesign institute. Yet, at the same time, it has eliminated departments such as biology, anthropology, geology, or sociology.

What makes ASU's Strategic Plan particularly interesting is that it strives for combining two objectives: (1) the plan will increase the university's size and expand its intellectual, pedagogical, and functional breadth. By engaging in a growth path, the university is endeavoring to simultaneously implement accessibility, inclusiveness, and quality; (2) the university has changed its organization, away from the departmental structure, to inter- and transdisciplinary centers, thereby hoping to increase its societal impact by tackling present and future grand challenges. Inevitably, with the momentum of growth and with the new design of the university, ASU was able to attract excellent academics that foster the culture of curiosity and creativity. 


\section{What Is Excellence in Strategic Planning?}

Excellence in strategic planning in universities not only requires a well-designed planning process, as described in the first part of this chapter. It also needs to focus on which profile the university would like to adapt. Should good teaching, even with an emphasis on excellent undergraduate education as at Princeton University, be a key factor? How research intensive should the university be? Should it pursue excellent research in targeted areas? How much will it strengthen research-based learning for students and foster the promotion of early stage researchers? Which entrepreneurial activities does a strategic plan need to have to better fund and change a university? How much can one rely on increasing the scale of a university, when combining the access of a more diverse student body with high quality of research and teaching? To what extent should a university tackle grand challenges and be engaged in solving problems of local communities? All these key issues were described in the chapter's second part. There are no clear-cut answers. They depend on the existing profile of an institution, external conditions, innovation challenges, and on the potential funding sources.

To complicate the search for an excellent strategic plan even further, let us remember that universities are likely to experience another big change in the near future. Higher education, through massively open online courses, as well as research, through online publications and the general availability of data in all fields, will become significantly more open and accessible. Higher education and research will be more accessible at low costs throughout the world. The innovation process will also be more open as firms will practice more outsourcing with respect to obtaining new ideas concerning products and production processes. Many more scientists and organizations, especially from developing countries and from outside of universities, will be able to engage in innovation issues. As with crowd funding of activities, there will be crowd research and crowd innovation.

"Open learning", "open science", and "open innovation" will make the borders of universities more permeable. As a consequence, education, and particular graduate education at universities, may become more important than research per se. Universities will enable people to participate in research and innovation endeavors of others, meeting research and innovation demands defined by society or by firms. Universities may then become certifying agents for those who actively engage in research and innovation elsewhere. They might then become marketing institutions to bring research and innovation more directly to the society and to the economy. In the future, a university will only thrive when it is well placed in a host of surrounding start-ups and applied or interdisciplinary research centers.

There will be more pressures on universities to meet the demands of knowledge societies to educate good researchers, particularly in the case of Ph.D. candidates [8]. The Ph.D. Education in many universities is still organized along traditional academic lines, with too narrow specializations, if it is organized at all. Interdisciplinary research and research in teams are rarely practiced in universities. 
Oversupply in the job markets for Ph.D.s in Germany or in the US indicates that the research formation at universities has to change in order to meet the new demands of knowledge societies.

\section{Summary}

What do we learn from international experiences on the role of strategic planning for an excellent university? Take into account the strengths and values of your traditions, and formulate high ambitions and coherent goals, which should be attainable at a specific date. Be ready to change the organization of the university. However, look closely at how the world is evolving. What ultimately counts is to attain an inherent resilience to uncertain developments. Egocentric, wishful thinking is misleading.

Open Access This chapter is distributed under the terms of the Creative Commons Attribution Noncommercial License, which permits any noncommercial use, distribution, and reproduction in any medium, provided the original author(s) and source are credited.

\section{References}

1. Christopher L. Eisgruber, A Strategic Look into Princeton's Future. Princeton Alumni Weekly, The President's Page, April 23, 2014, Vol.114, No.11.

2. Rexroth, Frank. (2011). Frankfurter Allgemeine Zeitung, 9(2), 33.

3. Wilhelm von Humboldt, Antrag auf Errichtung der Universität Berlin, Juli 1809, reprinted in: J.J.Engel et al., Gelegentliche Gedanken über Universitäten. Reclam-Verlag Leipzig 1990, pp. 267-283.

4. www.exzellenz.hu-berlin.de

5. Clark, B. R. (1998). Creating entrepreneurial universities. Organizational pathways to transformation. Oxford: Pergamon Press.

6. Clark, B. R. (2004). Delineating the Character of the Entrepreneurial University. Higher Education Policy, 17, 355-370.

7. Michael M. Crow, The Research University as Comprehensive Knowledge Enterprise: A Prototype for a New American University. In: Luc E. Weber, James J. Duderstadt (eds.), University Research for Innovation. Economica London-Paris-Geneva 2010, pp.211-225.

8. Nature, 472, 261. 